\title{
3D Mapping based-on Integration of UAV Platform and Ground Surveying
}

\author{
Muhammad Yazid Abu Sari ${ }^{1}$, Asmala Ahmad ${ }^{7}$, \\ Rozilawati Dollah ${ }^{8}$ \\ Centre of Advanced Computing Technology, Faculty of \\ Information Technology and Communication, Universiti \\ Teknikal, Malaysia ${ }^{1,7}$ \\ School of Computing Faculty of Engineering, UTM Johor \\ Bahru, Johor, Malaysia ${ }^{8}$
}

\author{
Abd Wahid Rasib ${ }^{2}$, Hamzah Mohd $\mathrm{Ali}^{3}$, Abdul Razak \\ Mohd Yusoff ${ }^{4}$, Muhammad Imzan Hassan ${ }^{5}$, \\ Khairulnizam M.Idris ${ }^{6}$ \\ Tropical Map Research Group \\ Faculty of Built Environment and Surveying, UTM \\ Johor Bahru, Johor, Malaysia
}

\begin{abstract}
Development in aerial photogrammetry technology has contributed a notable impact to the area of large-scale mapping. Nowadays, unmanned aerial vehicle (UAV) platform has become a significant tool in aerial mapping. Generating 3D mapping using photos acquired from UAV is more preferable due to its low cost and flexible operation. Therefore, this study aims to develop a technique for 3D mapping with an integration of UAV aerial photos and detailed ground survey. The produced 3D mapping has $\operatorname{RMSE}(x)=0.279, \operatorname{RMSE}(y)=0.215$, and $\mathrm{RMSE}$ (z) $=1.341$ using 25 randomly selected sample points. Besides that, the result shows the location parameters i.e. $x, y$ and $z$ were also positively correlated, $t$-test $(x)=0.961$, $t$-test $(y)=0.250$ and $t$ test $(z)=1.885$, respectively.
\end{abstract} photo

Keywords-3D mapping; UAV platform; ground survey; aerial

\section{INTRODUCTION}

The rapid advancement in aerial photogrammetry technology, particularly in the area of digital scanning has produced a new means to create a photorealistic 3D model. 3dimensional image or also known as 3D image is commonly understood when an image contains the information regarding the depth or height of objects within the image. In realising 3D image production using aerial photos, flight planning parameters and ground control points (GCP) need to be taken into account. GCP is used for georeferencing, which is linking photos with spatial locations. These photos need to further undergo stitching process in order to produced seamless aerial photos of an area, known as aerial orthophoto. The orthophoto can be further processed to generate digital surface model (DSM) and digital terrain model (DTM) in which to be used in producing the 3D mapping. A number of studies related to 3D mapping based on aerial can be found however, accuracy is still an issue. There are effort to look into this issue by researchers in manufacturing-based countries such as USA, China, Japan and UK. Nevertheless, not much effort have been carried out in developing countries such as Malaysia despite having different condition in terms of climate, terrains and land covers in which may have effects on the accuracy. Therefore, this study attempts to further look into the accuracy issue by making use of an approach where aerial photos and ground details are integrated in producing 3D maps.
Nowadays, 3D city mapping can be easily implemented with the advancement of low cost unmanned aerial vehicle (UAV). A 3D city mapping represents an urban environment with three-dimensional geometry of structures and urban objects, with the building as the most prominent features [14]. A typical 3D city mapping is derived from various data acquisition techniques, for instance, photogrammetry and laser scanning [5-8], extrusion from 2D footprints $[9,10]$, synthetic aperture radar [11-15], architectural models and drawings [16-18], handheld devices [19,20], procedural modelling [2126], and volunteered geoformation [27-29].

Meanwhile, the acquisition of aerial photos using UAV platform becomes an efficient optional compared to other methods. Here, UAV allows a higher degree of automation in aerial photos collection [30]. Furthermore, UAV offers a lowcost alternative and a real-time application compared to other classical manned aerial photogrammetry [31]. In addition, UAV photos are also have been proved that applicable in generating high-quality $3 \mathrm{D}$ view [31-33]. Subsequently, UAV flown at low altitude (20-30 meters) can produce a ground pixel less than $5 \times 5 \mathrm{~cm}$ which gives a better resolution for low-cost mapping approach [34].

Numerous research studies have been conducted in term of UAV photogrammetry [35-40] for 3D mapping and modelling. For example, Hudzietz and Saripalli [41] have successfully employed the structure from motion (SfM) techniques for the reconstruction of aerial landscapes imagery. Zhiguang Ding and other scholar verified the superiority of UAV for rapid modelling compared to artificial modelling where the aerial photos were ultimately converted into a 3D image of terrain [42]. The researchers proved that UAV has been used as a platform for aerial photo acquisition. This offers effective and accurate large-scale terrain modelling with cost-efficient solution. Therefore, this study aims to produce a 3D map based on the integration of UAV platform and ground detail survey at 725 acres of the main campus in UTeM, Melaka, Malaysia.

\section{ISSUES}

Unmanned aerial vehicle (UAV) is a flexible aerial photography platform widely used in various applications 
such as mapping, agriculture, 3D documentation and more. Due to benefits provided by UAV, there is no doubt that UAV can be used as tools and sources for data collection. However, despite the numerous benefits, UAV photos are exposed to degradation resulted from issues related to imaging stability. Generally, ordinary UAV considered as lightweight platform which highly influenced by environmental conditions, such as wind [43]. During flight, altitude instability can be caused by wind and other weather factors may lead to a large rotation angle for UAV platform. Large rotation angle from UAV will decrease aerial photo quality and results in photo deformation that will affect their overlaps during stitching process. The insufficient feature overlap between photos may lead to the failure of stitched image reconstruction [44]. Based on the mentioned issue, this will greatly affect the accuracy of the end product that are produced for mapping and 3D documentation. Thus, this study attempts to show the accuracy of 3D mapping that was developed using aerial photos from UAV.

\section{STUDY AREA}

The location of the study area is UTeM main campus as shown in Figure 1, located in Durian Tunggal, Malacca (Latitude, 2.309980, Longitude 102.317672). The campus coverage area approximately 725 acres and situated near to the bustling historical city of Malacca. UTeM campus which consists of 23 main building and 7 of it is faculty building. For this study, the built-up area at the center of UTeM campus was the main focus where the major buildings are chancellery building, student activity center, mosque, and main hall respectively. The tallest building that recorded for this study is the main hall of UTeM which is 20 meters above mean sea level (MSL). UTeM campus can be easily accessed through Ayer Keroh Toll exit and approximately 20 minutes away from the main city.

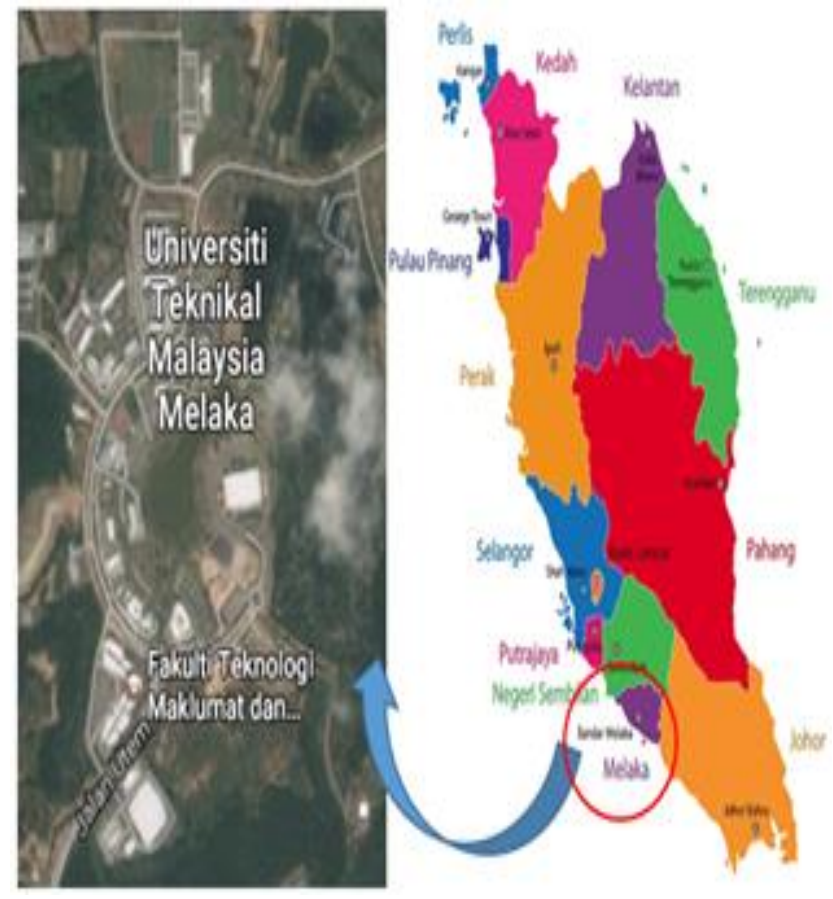

Fig. 1. Area of Study (Source Google Earth).

\section{METHODOLOGY}

This part describes the workflow for this study. During the early stages of the study, a set of the flowchart is created to make sure the study conducted properly and efficiently. based on Figure 2, the research methodology consists of four (4) main phases which are preliminary study, data acquisition, data processing and results. The first phase is the preliminary study. This phase generally shows the planning process and how the study will be conducted as shown in Figure 2. Preliminary study is essential before conducting any research studies.

In Phase 2, data acquisition focuses mainly the process in obtaining the required data for the study which is ground survey and aerial photos using UAV platform. In ground survey, first, the establishment of ground control point will be conducted followed by detailed survey as the control point will provide referral coordinates for the detailed survey. The flight planning for UAV is created using photogrammetry system and camera calibration for the non-matrix camera is carried out in order to reduce the bundle of error for the orthophoto generation.

Phase 3 describes the process of data processing for ground survey data and aerial photo in order to obtain DSM, DTM, 3D vector and orthophoto respectively. Lastly, Phase 4 is the result and analysis. The result of the study is a 3D orthophoto and 3D vector map of the study area. For accuracy assessment, calculation of RMSE and t-test are implemented.

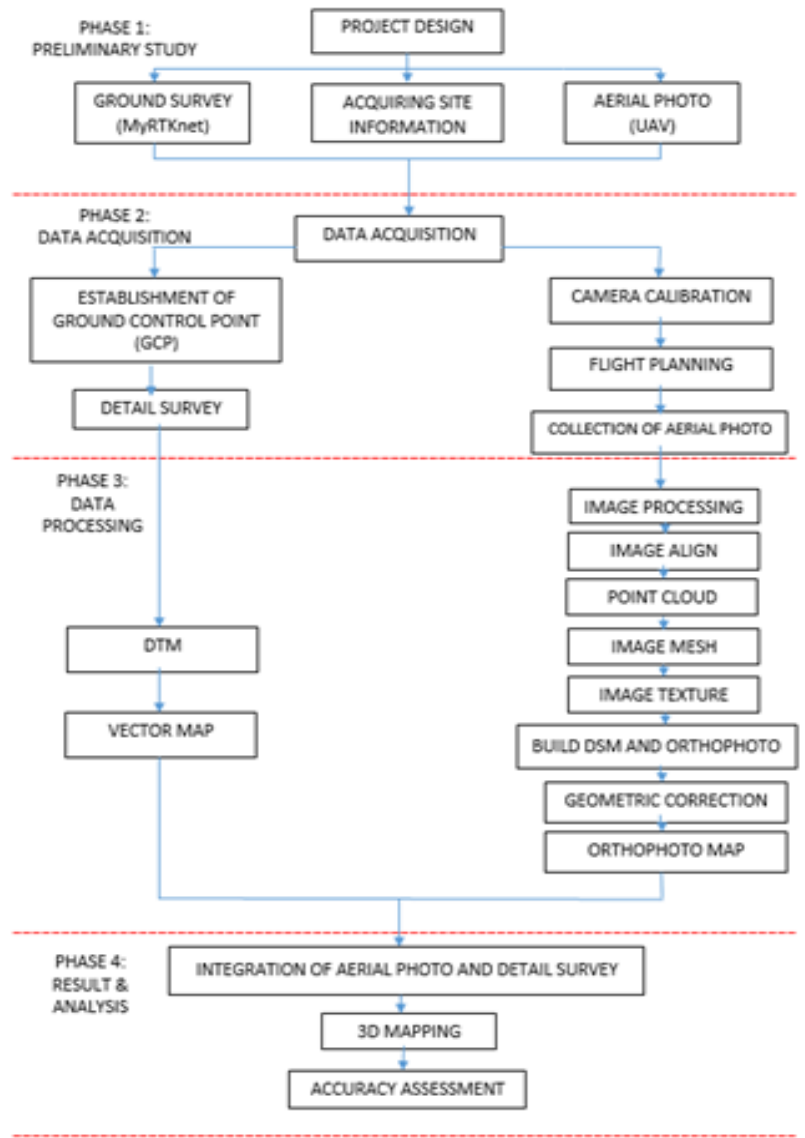

Fig. 2. Flowchart of Study. 


\section{A. Data Acquisition}

The process of data collection is conducted based on the project frameworks that were collected in the preliminary study. This is to ensure the collected data met the scope of this study. Data collection involves two main parts; primary data and secondary data. For primary data, it involves the collection of aerial photo using non-matrix camera payload UAV platform. Whereas secondary data is ground survey is using GPS and total station.

The data acquisition begins with the establishment of ground control point GCP'S followed by detail survey. The establishment of GCP is done by using GPS Trimble GR-5 at the selected control station. The collection of detailed ground survey data consists several survey tools such as reflectorless total station, handheld GPS and Topcon GPS GR5 respectively in order to obtain the coordinates and elevation $(\mathrm{x}, \mathrm{y}, \mathrm{z})$ of the feature point.

For the aerial photo, the flight planning of the UAV is conducted and installed in the laboratory by using open source software. In addition, camera calibration has also been conducted to photo distortion. UAV XR Q30 Pro is used for the whole process for collecting the photos.

\section{B. Establishment of Ground Control Point}

The establishment of GCPs is a very important stage in the photogrammetric mapping [45]. In this study, ten (10) ground control points have been established. In order to complete the observation of every ground control point, GPS static observation method is applied within 30 minutes' observation for every station. This method is suitable to establish control point at the wide area with sub-centimeter accuracy. GPS observation for control point shall be carried out radially. The concept is known to coordinate at base station and it has been used to compute carrier phase correction in observation. The data observation will be processed using Trimble Total Control software and all coordinates subsequently transformed from WGS84 to local coordinate GDM2000 RSO as shown in Table 1.

TABLE I. COORDINATES OF GCP'S

\begin{tabular}{|l|l|l|l|l|}
\hline Station & \multicolumn{2}{|l}{ WGS84 } & \multicolumn{2}{l|}{ GDM2000 RSO } \\
\hline 1 & 102.323 & 2.312 & 480602.317 & 255768.550 \\
\hline 2 & 102.323 & 2.311 & 480600.904 & 255718.090 \\
\hline 3 & 102.320 & 2.309 & 480347.303 & 255457.218 \\
\hline 4 & 102.320 & 2.309 & 480351.282 & 255509.274 \\
\hline 5 & 102.318 & 2.310 & 480122.095 & 255595.380 \\
\hline 6 & 102.318 & 2.310 & 480127.291 & 255585.059 \\
\hline 7 & 102.319 & 2.311 & 480184.663 & 255663.234 \\
\hline 8 & 102.319 & 2.311 & 480244.406 & 255653.314 \\
\hline 9 & 102.319 & 2.312 & 480176.377 & 255818.904 \\
\hline 10 & 102.319 & 2.312 & 480154.621 & 255767.354 \\
\hline
\end{tabular}

\section{Primary Data}

Primary data involves the acquisition of aerial photo using Unmanned Aerial Vehicle (UAV). UAV refers to an aircraft that fly without an onboard human pilot. UAV can be remotely controlled from the ground station or flown autonomously based on the pre-programmed flight planning that installed before the UAV's flown. For this study, a model of UAV XR Q350 Pro that weight $3 \mathrm{~kg}$ is used as shown in Figure 3 and the specification of the UAV is shown in Table 2. Furthermore, UAV can maintain a flight time for 25 minutes. UAV is mounted with non-matrix camera model Canon Powers hot XS260 with focal length 4.5-90.0 $\mathrm{mm}$ as shown in Figure 4 and the specifications are mentioned in Table 3.

The UAV maneuvers at altitude average of $100 \mathrm{~m}$ above ground in this study. Each photo have $50 \%$ overlap, $65 \%$ side lap and a total of 7228 photos were processed using the photogrammetric system. Figure 5 shows a sample aerial photo. The photos then underwent stitching process in order to produce the orthophoto of the study area. In addition, the digital surface model (DSM) and a digital terrain model (DTM) were also produced. The whole process is conducted using $i 7$ processor with 16 GB RAM.

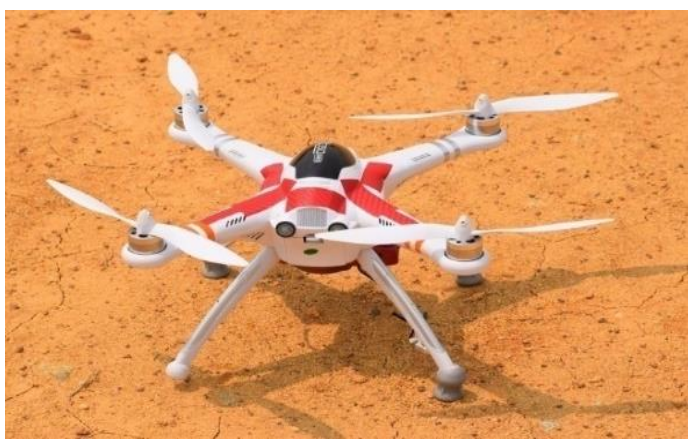

Fig. 3. XR Q30 Pro.

TABLE II. SPECIFICATIONS OF XR Q350 PRO UAV

\begin{tabular}{|l|l|}
\hline Criteria & Specification \\
\hline Main Rotor Diameter & $556 \mathrm{~mm}$ \\
\hline Main Rotor Blade Length & $206 \mathrm{~mm}$ \\
\hline Length & $289 \mathrm{~mm}$ \\
\hline Width & $289 \mathrm{~mm}$ \\
\hline Height & $200 \mathrm{~mm}$ \\
\hline Brushless Motor & WK-WS-28-008A \\
\hline Brushless ESC & WST-15A(G/R) \\
\hline Receiver & RX703 \\
\hline Flight Time & 25 minutes \\
\hline
\end{tabular}

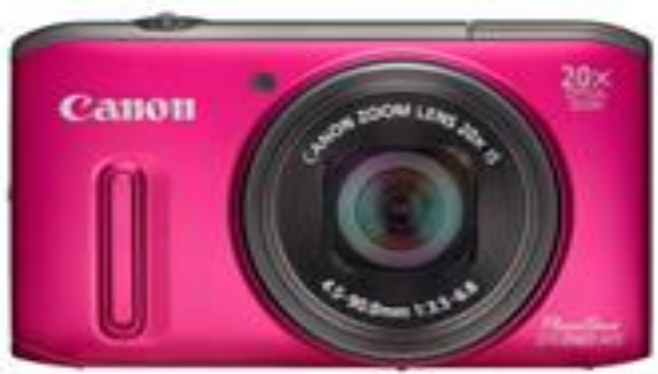

Fig. 4. Canon Powershot XS260 Camera. 
TABLE III. SPECIFICATIONS OF CANON POWERSHOT XS260 CAMERA

\begin{tabular}{|l|l|}
\hline Criteria & Lens \\
\hline Focal Length & $4.5-90.0 \mathrm{~mm}(35 \mathrm{~mm}$ equivalent: $25-500 \mathrm{~mm})$ \\
\hline Zoom & $\begin{array}{l}\text { Optical 20x } \\
\text { Zoom Plus 39x } \\
\text { Digital Approx. 4.0x (with Digital Tele-Converter } \\
\text { Approx. 1.5x or 2.0x and Safety Zoom } 1 \text { ). Combined } \\
\text { Approx. 80x }\end{array}$ \\
\hline $\begin{array}{l}\text { Maximum } \\
\text { f/number }\end{array}$ & f/3.5 - f/6.8 \\
\hline Construction & $\begin{array}{l}12 \text { elements in 10 groups (1 UA lens, 2 double-sided a } \\
\text { spherical lens) }\end{array}$ \\
\hline $\begin{array}{l}\text { Image } \\
\text { Stabilization }\end{array}$ & Yes (lens shift-type), 4-stop. Intelligent IS \\
\hline Effective Pixels & Approx. 12.1M \\
\hline
\end{tabular}

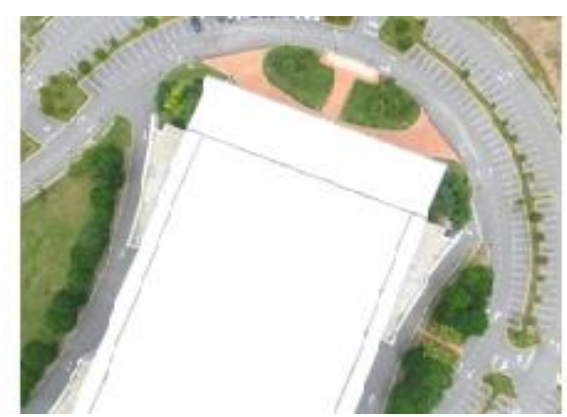

Fig. 5. Aerial Photo of the Study Area.

\section{Secondary Data}

Secondary data involves the data acquisition of ground survey. In this study, the RTK GPS's surveying technique is used for detailed ground survey. Real-Time Kinematic (RTK) technique is used to improve the precision of the position data derived from satellite-based positioning system. In addition, RTK techniques enable the study to obtain centimeter-level positioning which considered relevant for this study. The system used in this study is Malaysian Real-Time Kinematic GNSS Network (MyRTKnet). MyRTKnet is a system based on a network of seventy-eight (78) global navigation satellite system (GNSS) reference station continuously connected via internet protocol virtual private network (IPVPN) to the control center. At the control center, the computer processor will gather the information from all GPS receiver and creates a living database of Regional Area Connection.

The collections of detailed data were such as spot height, road junctions and other types of data utility. The detailed survey will be processed using CDS (civil design and survey) and AutoCAD. This system was employed to digitize and join the detailed survey data which is obtained using GPS devices and handheld GPS as shown in Figure 6 and Figure 7, respectively. The GPS devices used for this study is Topcon GPS GR-5 and the specification is mentioned in Table 4. Whereas, reflectorless total station shown in Figure 8 will be used to collect the detailed survey of UTeM such as building heights and building edges. The specification of the reflectorless total station as stated in Table 5. Topography map for this study is produced based on the compilation of MyRTKnet and reflectorless total station data. While 3D vector data have been generated from this ground survey.

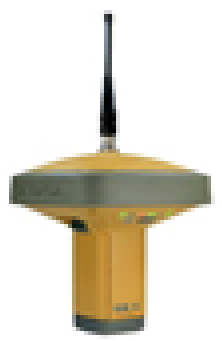

Fig. 6. Topcon GPS GR-5.

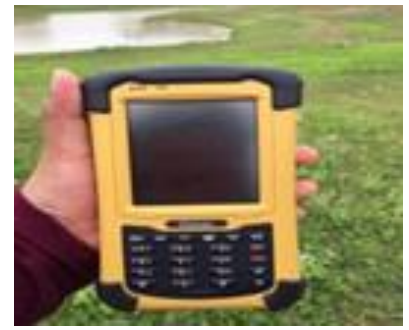

Fig. 7. Handheld GPS.

TABLE IV. TOPCON GPS GR-5 SPECIFICATION

\begin{tabular}{|c|c|}
\hline \multicolumn{2}{|l|}{ GNSS } \\
\hline Signals Tracked & $\begin{array}{l}\text { GPS: L1, L1C, L2, L2C, and L5 } \\
\text { GLONASS: L1, L2 } \\
\text { Galileo*: E1, E5a, E5b, AltBOC } \\
\text { BeiDou: B1, B2 } \\
\text { SBAS L1 C/A WAAS/MSAS/EGNOS } \\
\text { QZSS L1 C/A, L1C, L2C }\end{array}$ \\
\hline $\begin{array}{l}\text { Number of } \\
\text { Channels }\end{array}$ & $\begin{array}{l}\text { 226-Channel Vanguard Technology with Universal } \\
\text { Tracking Channels capable of All-in-View tracking }\end{array}$ \\
\hline Antenna Type & Integrated Fence Antenna (1) with Ground Plane \\
\hline \multicolumn{2}{|l|}{ Accuracy } \\
\hline Static & $\begin{array}{l}\mathrm{H}: 3 \mathrm{~mm}+0.1 \mathrm{ppm}(2) \\
\mathrm{V}: 3.5 \mathrm{~mm}+0.4 \mathrm{ppm}(2)\end{array}$ \\
\hline RTK & $\begin{array}{l}\mathrm{H}: 5 \mathrm{~mm}+0.5 \mathrm{ppm} \\
\mathrm{V}: 10 \mathrm{~mm}+0.8 \mathrm{ppm}\end{array}$ \\
\hline
\end{tabular}

Fig. 8. Topcon Total Station FS 105.

TABLE V. TOPCON TOTAL STATION FS 105 SPECIFICATION

\begin{tabular}{|c|c|}
\hline \multicolumn{2}{|l|}{ Specification } \\
\hline Display & $\begin{array}{l}\text { Dual backlit LCD (ES-107 Single } \\
\text { Display) }\end{array}$ \\
\hline Battery Operation & Up to 36 hours \\
\hline Wireless Connection & Bluetooth $®$ Class 1 \\
\hline Operating Temperature & $-20^{\circ} \mathrm{C}$ to $+60^{\circ} \mathrm{C}$ \\
\hline
\end{tabular}




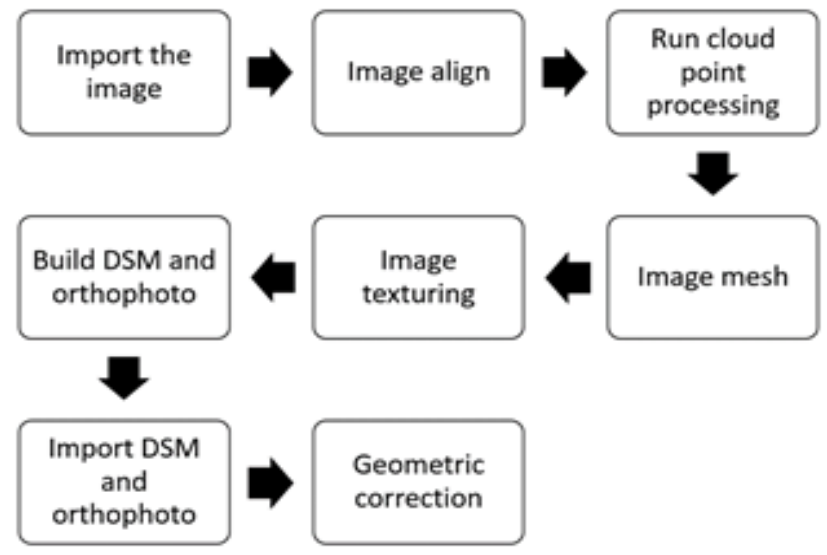

Fig. 9. Flowchart of Image Processing.

\section{E. Data Processing}

The aerial photo from UAV will undergo several processes in order to produce the orthophoto of the study area. The first step in producing orthophoto is photo alignment which shows the position and orientation of the photos. In addition, the sparse cloud that produced in this step will reveal the whole area of the study. After the photo alignment, the reconstruction of dense point cloud will be done. It enables the orthophoto that produces in higher detail. Furthermore, the photo alignment is depending on digital matching technique and space intersection using the system.

The following steps are used in photo meshing and texturing. Photo meshing is a process to turn discrete point cloud data into continuous 3D surface and it is constructed in the form of triangulated irregular network (TIN) [46]. In addition, texturing is a process of projecting the texture from the original photo to the model surface [46]. Finally, orthophoto and digital surface model (DSM) were produced. The whole process is shown in Figure 9. The produced orthophoto will undergo geometric corrections in order to transform the coordinates from WGS84 to local coordinate (GDM2000 RSO).

The ground survey data will be processed using Trimble Total Center (TTC) system. Whereby a detailed survey will be processed by using CDS (civil design \& survey) and AutoCAD, respectively. The raw data that obtained from the reflectorless total station will be imported to CDS in order to generate the contour line and ground features details. After that, import the data into AutoCAD to join the details. Through this process vector map of the study area will be produced.

\section{F. Generating 3D from Aerial Photo and Detail Survey}

The generation of 3D from aerial photo involves two main components which are orthophoto and Digital Surface Model (DSM). The produced orthophoto will provide the location of the object in term of $\mathrm{x}$ and $\mathrm{y}$ positioning. Subsequently, the digital surface model (DSM) will provide the $\mathrm{z}$ values which is the height of an object. By using the module that existed in a GIS system, the DSM value will be referred as the base height and been applied to the orthophoto (2D) in order to produce a 3D model of an object as shown in the results' section.
The process is repeated in order to produce a $3 \mathrm{D}$ vector map. While compared to aerial photo the vector drawing that produces from AutoCAD contain the values of $\mathrm{z}$. Thus using the module in the GIS system, a 3D vector map can be produced from 2D vector map.

\section{RESULTS}

Based on the obtained aerial photo, the orthophoto and DSM for the study area can be produced. Hence, these data can be used to produce a 3D model of the study area. For the obtained featured points through ground detailed survey, it can be used to produce a 3D vector of the study area.

\section{A. 3D Modelling and Orthophoto}

Through the data processing, vector map and orthophoto of UTeM main campus are shown in Figure 10 and Figure 11, respectively. In addition, using CDS and AutoCAD system, 3D vector map can be generated as shown in Figure 12. The generated of DSM from the aerial photo will be used to provide height value for orthophoto in order to produce a 3D map based on aerial photo for UTeM main campus (refer to Figure 13). Whereas, Figure 14, Figure 15 and Figure 16 shows the images and $3 \mathrm{D}$ visualization of the selected buildings.

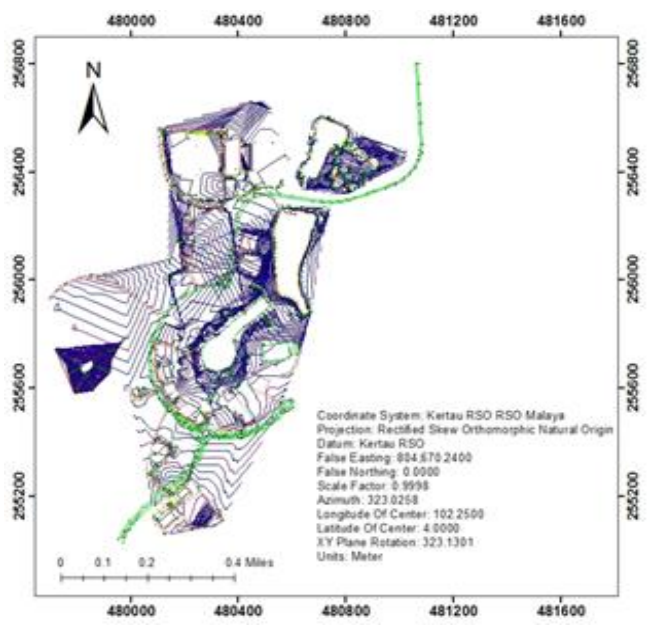

Fig. 10. Vector Map of UTeM Main Campus.

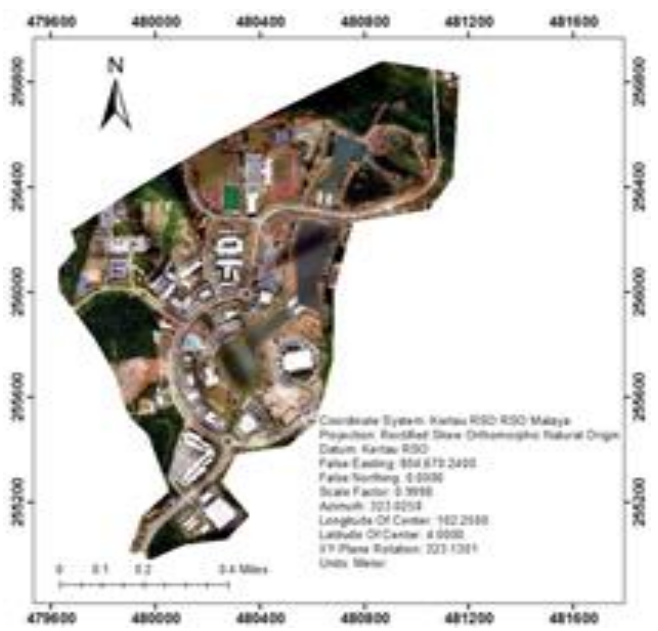

Fig. 11. Orthophoto of UTeM Main Campus. 


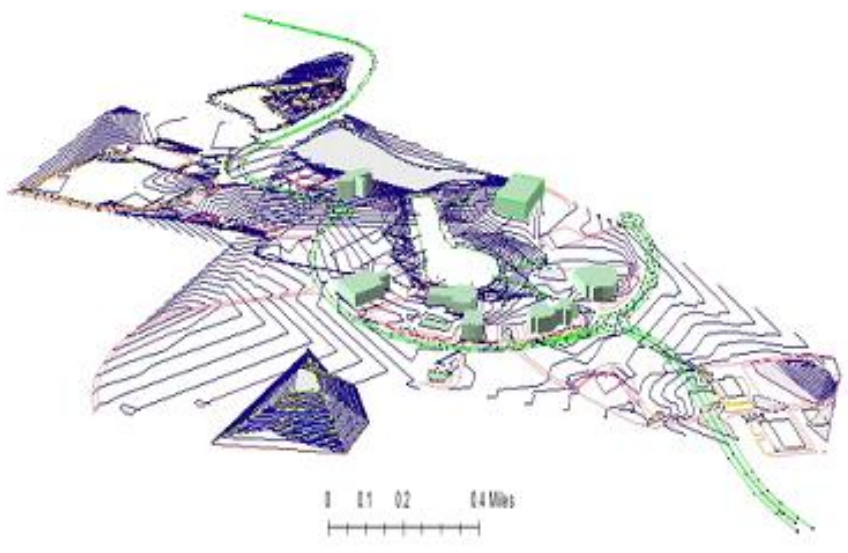

Fig. 12. 3D Vector Map of UTeM Main Campus.

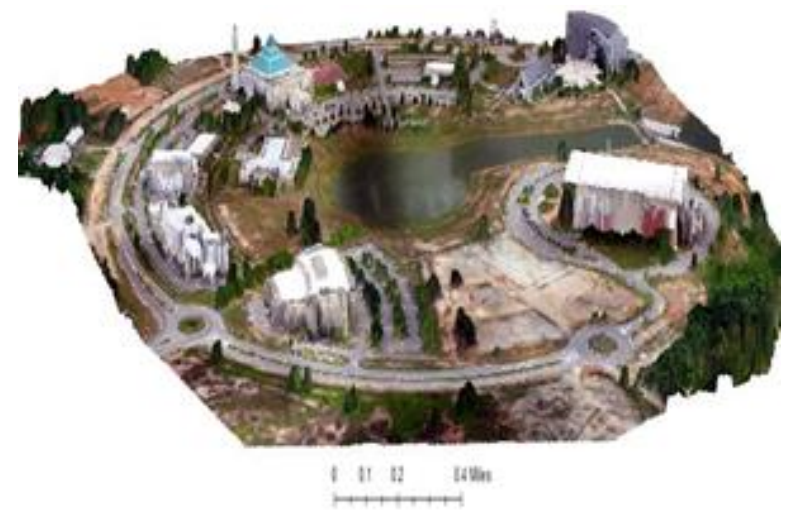

Fig. 13. 3D Visualization of the Study Area.

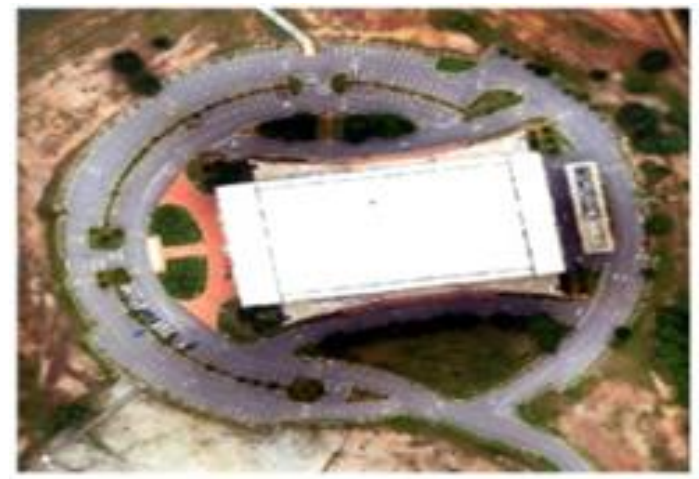

(2D)

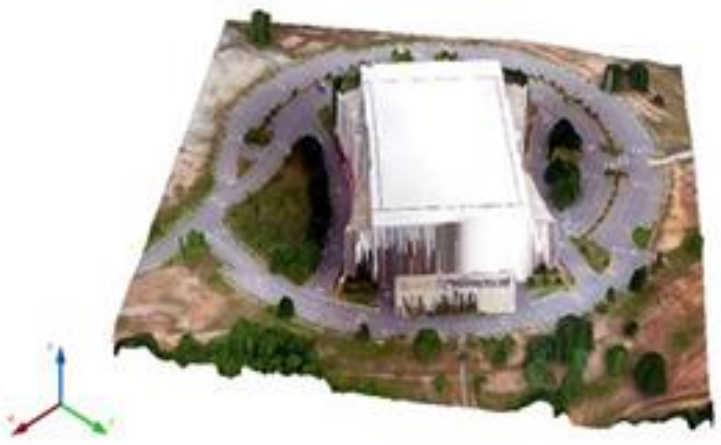

(3D)

Fig. 14. 2D and 3D Map of the Main Hall.

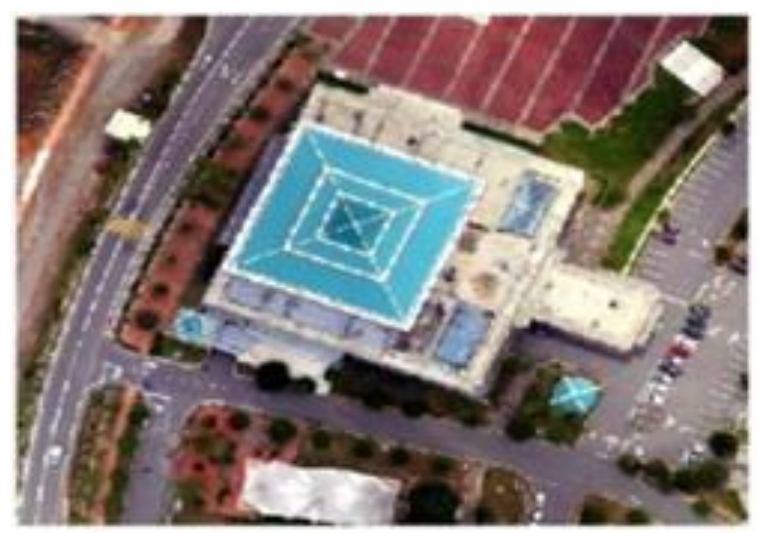

(2D)

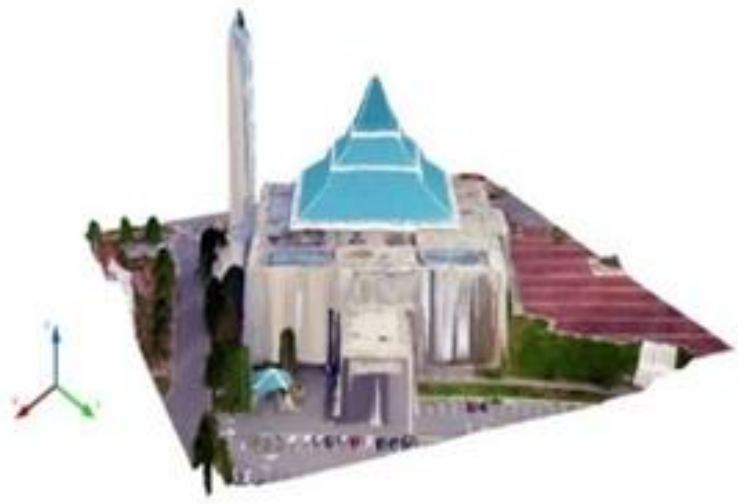

(3D)

Fig. 15. 2D and 3D Map for Mosque.

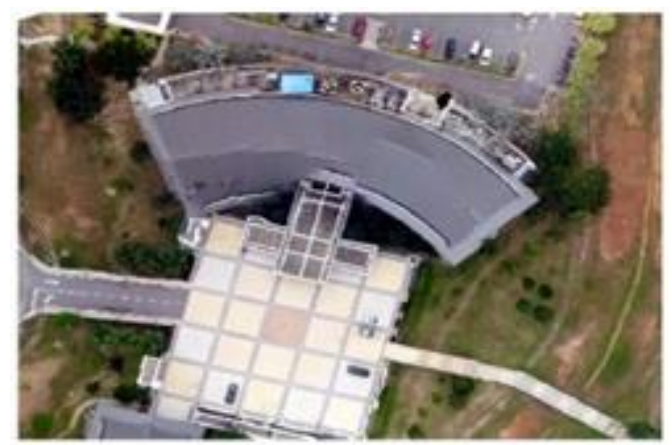

(2D)

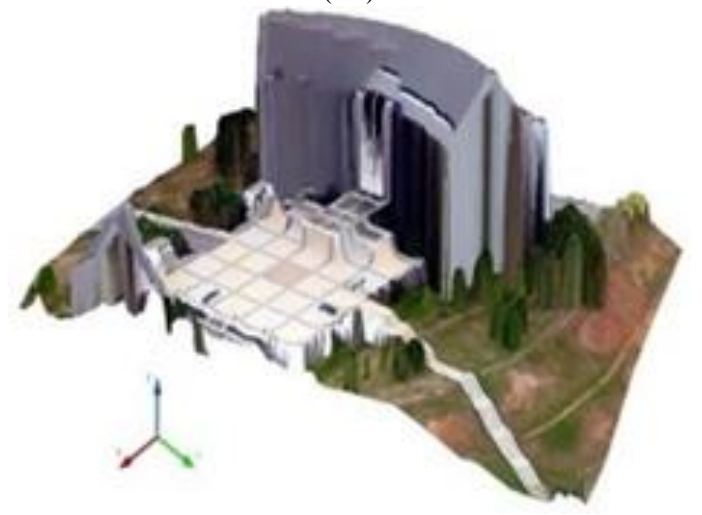

(3D)

Fig. 16. 2D and 3D Map for Chancellery Hall. 


\section{ANALYSIS}

In this section, the quantitative analysis was carried out to show the accuracy for this study. Quantitative analysis is a technique that used to understand the behaviour of the data through mathematical or statistical modelling. Quantitative assessment is implemented by calculating the root mean square error (RMSE) from two different data sources. This study will show the quantitative assessment in term of location or positions which are ( $\mathrm{x}$ and $\mathrm{y}$ ) and height $(\mathrm{z})$ from detailed ground survey and raster images from UAV respectively.

$\mathrm{RMSE}=\sqrt{\frac{\Sigma(\mathrm{n} 1-\mathrm{n} 2)^{2}}{N}}$

Where

$n 1-n 2=$ difference between two parameters

$\mathrm{N}=$ total number of points

TABLE VI. TwENTY-FIVE (25) SAMPLE POINTS FROM VeCTOR MAP

\begin{tabular}{|c|c|c|c|}
\hline Point & Vector(x) & Vector(y) & Vector $(z)$ \\
\hline 1 & $480,197.70$ & $255,668.09$ & 57.53 \\
\hline 2 & $480,221.08$ & $255,676.68$ & 57.53 \\
\hline 3 & $480,195.39$ & $255,635.18$ & 57.53 \\
\hline 4 & $480,210.32$ & $255,635.77$ & 57.53 \\
\hline 5 & $480,244.16$ & $255,653.55$ & 57.53 \\
\hline 6 & $480,117.81$ & $255,605.85$ & 67.08 \\
\hline 7 & $480,133.18$ & $255,575.90$ & 67.08 \\
\hline 8 & $480,168.58$ & $255,597.98$ & 67.08 \\
\hline 9 & $480,156.69$ & $255,621.80$ & 67.08 \\
\hline 10 & $480,334.94$ & $255,458.03$ & 66.66 \\
\hline 11 & $480,314.16$ & $255,482.27$ & 66.66 \\
\hline 12 & $480,392.47$ & $255,487.70$ & 66.66 \\
\hline 13 & $480,351.39$ & $255,534.90$ & 66.66 \\
\hline 14 & $480,608.37$ & $255,726.83$ & 56.98 \\
\hline 15 & $480,602.09$ & $255,769.41$ & 56.98 \\
\hline 16 & $480,611.92$ & $255,769.64$ & 56.98 \\
\hline 17 & $480,151.53$ & $255,546.07$ & 56.46 \\
\hline 18 & $480,169.13$ & $255,554.52$ & 56.46 \\
\hline 19 & $480,031.48$ & $255,570.24$ & 58.84 \\
\hline 20 & $480,010.63$ & $255,573.74$ & 58.84 \\
\hline 21 & $480,005.62$ & $255,589.43$ & 58.84 \\
\hline 22 & $480,021.15$ & $255,601.94$ & 58.84 \\
\hline 23 & $480,454.55$ & $255,997.24$ & 69.87 \\
\hline 24 & $480,399.01$ & $256,037.18$ & 69.87 \\
\hline 25 & $480,396.22$ & $256,031.12$ & 69.87 \\
\hline
\end{tabular}

TABLE VII. TwENTY-FIVE (25) SAMPLE POINTS FROM ORTHOPHOTO

\begin{tabular}{|l|l|l|l|}
\hline Point & Orthophoto(x) & Orthophoto(y) & Orthophoto(z) \\
\hline 1 & $480,197.37$ & $255,668.20$ & 55.05 \\
\hline 2 & $480,221.33$ & $255,676.90$ & 55.05 \\
\hline 3 & $480,195.26$ & $255,634.92$ & 55.05 \\
\hline 4 & $480,210.19$ & $255,635.65$ & 55.05 \\
\hline 5 & $480,244.34$ & $255,653.46$ & 55.05 \\
\hline 6 & $480,117.83$ & $255,605.90$ & 67.81 \\
\hline 7 & $480,133.15$ & $255,575.81$ & 67.81 \\
\hline 8 & $480,168.69$ & $255,597.84$ & 67.81 \\
\hline 9 & $480,156.71$ & $255,621.92$ & 67.81 \\
\hline 10 & $480,334.96$ & $255,458.21$ & 66.99 \\
\hline 11 & $480,314.27$ & $255,482.29$ & 66.99 \\
\hline 12 & $480,392.53$ & $255,487.95$ & 66.99 \\
\hline 13 & $480,351.48$ & $255,535.02$ & 66.99 \\
\hline 14 & $480,608.41$ & $255,726.50$ & 55.07 \\
\hline 15 & $480,602.29$ & $255,768.68$ & 55.07 \\
\hline 16 & $480,611.88$ & $255,769.96$ & 55.07 \\
\hline 17 & $480,151.56$ & $255,546.07$ & 56.52 \\
\hline 18 & $480,169.25$ & $255,554.55$ & 56.52 \\
\hline 19 & $480,031.41$ & $255,570.13$ & 58.92 \\
\hline 20 & $480,010.62$ & $255,573.81$ & 58.92 \\
\hline 21 & $480,005.55$ & $255,589.44$ & 58.92 \\
\hline 22 & $480,021.16$ & $255,601.98$ & 58.92 \\
\hline 23 & $480,454.53$ & $255,997.49$ & 70.34 \\
\hline 24 & $480,398.34$ & $256,037.14$ & 70.34 \\
\hline 25 & $480,395.15$ & $256,030.97$ & 70.34 \\
\hline & & & \\
\hline
\end{tabular}

Twenty-five (25) points that randomly selected distributed around the study area were used as the sample point for RMSE calculation (refer to Table 6 and Table 7). By using equation (1) this study managed to obtain RMSE value for coordinates $(\mathrm{x}$ and $\mathrm{y})$ and height $(\mathrm{z})$ which are $\operatorname{RMSE}(\mathrm{x})=$ $0.279, \operatorname{RMSE}(\mathrm{y})=0.215$, and $\operatorname{RMSE}(\mathrm{z})=1.341$, respectively. This study also conducts pair sample t-test in order to produce a concrete result. Paired sample t-test is a statistical procedure that used to determine whether the mean differences for two set of selected observation is zero. The parameters for paired sample t-test are coordinates ( $\mathrm{x}$ and $\mathrm{y}$ ) and height $(\mathrm{z})$ that obtain from 3D raster (refer to Figure 13) and 3D vector (refer to Figure 12). Table 8 and Table 9, respectively show the results for the pair sample correlation and pair sample test respectively.

TABLE VIII. PAIR SAMPLE CORRELATIONS

\begin{tabular}{|l|l|l|}
\hline & N & Correlation \\
\hline X_vector \&X_raster & 25 & 1.000 \\
\hline Y_vector \&Y_raster & 25 & 1.000 \\
\hline Z_vector \& Z_raster & 25 & 0.990 \\
\hline
\end{tabular}

TABLE IX. PaIR SAmple Test

\begin{tabular}{|l|l|l|l|l|}
\hline & \multirow{2}{*}{ Mean } & \multicolumn{2}{|c|}{$\begin{array}{l}\text { 95\% Confidence Interval } \\
\text { of the Difference }\end{array}$} & \multirow{2}{*}{$\mathrm{t}$} \\
\cline { 2 - 4 } & & Lower & Upper & \\
\hline $\begin{array}{l}\text { X_vector - } \\
\text { X_raster }\end{array}$ & 0.053 & -0.061 & 0.168 & 0.961 \\
\hline $\begin{array}{l}\text { Y_vector - } \\
\text { Y_raster }\end{array}$ & 0.010 & -0.079 & 0.101 & 0.250 \\
\hline $\begin{array}{l}\text { Z_vector - } \\
\text { Z_raster }\end{array}$ & 0.481 & -0.045 & 1.008 & 1.885 \\
\hline
\end{tabular}


Based on Table 8 above, the result shows that the parameter obtained from the $3 \mathrm{D}$ vector and $3 \mathrm{D}$ raster for coordinates ( $\mathrm{x}$ and $\mathrm{y})$ and height $(\mathrm{z})$ were positively correlated which are $\mathrm{x}=1.000, \mathrm{y}=1.000$ and $\mathrm{z}=0.990$ respectively. While Table 9 illustrated the pair sample test, indicates $\mathrm{x}$ coordinates for the $3 \mathrm{D}$ vector are 0.053 , higher than $3 \mathrm{D}$ raster with $95 \%$ confidence interval $[-0.061,0.168]$. Meanwhile, the test shows $\mathrm{y}$-coordinates for $3 \mathrm{D}$ vector is 0.010 higher than $3 \mathrm{D}$ raster with $95 \%$ confidence interval $[-0.079,0.101]$. Lastly, the height $(\mathrm{z})$ from $3 \mathrm{D}$ vector was 0.4815 higher than $3 \mathrm{D}$ raster with $95 \%$ confidence interval [-0.045, 1.008].

\section{CONCLUSION}

This paper has presented the use of the unmanned aerial vehicle (UAV) in generating 3D mapping for UTeM, Malacca. This study shows that aerial UAV photos can be used to generate 3D models of features within the selected study area. Even though the generated 3D models do not look alike in the real world, but it manages to outline the shape of the features, for example, the chancellor hall and mosque with good planimetric accuracy rates. However, this study concluded that the accuracy can be improved especially for the height $(\mathrm{z})$ by changing the aerial flight type to oblique photograph instead of vertical photograph or nadir as used in this study (refer to Figure 17).

The implementation of the UAV platform in this study can be described as a low-cost method or approach using closerange photogrammetry in generating large-scale of 3D map compared to other type of conventional methods. Thus, the integration of UAV platform aerial photo and ground detailed survey can be used to produce a large-scale of 3D mapping.

In addition, the result of this study is well supported using accuracy assessments which are RMSE and paired sample ttest. The obtained RMSE values for $\mathrm{x}, \mathrm{y}$ and $\mathrm{z}$ from 25 distributed points are $\mathrm{RMSE}_{X}=0.279, \mathrm{RMSE}_{\mathrm{Y}}=0.215$ and $\mathrm{RMSE}_{\mathrm{Z}}=1.341$ respectively. For paired sample t-test, the coordinates ( $\mathrm{x}$ and $\mathrm{y}$ ) and height $(\mathrm{z}$ ) from both data were positively correlated.

Furthermore, the study also managed to fulfill the criteria to produce a 3D city model. According to cityGML (Architectural models) there are five (5) types of Level of Detail that used to facilitate efficient visualization and data analysis which are Level of Detail 0 (LOD0), Level of Detail 1 (LOD1), Level of Detail 2 (LOD2), Level of Detail 3 (LOD3) and Level of Detail 4 (LOD4). The positional and height accuracy for each Level of Detail is LOD0 (less than LOD1), LOD1 (5m or less), LOD2 ( $2 \mathrm{~m}$ or better), LOD3 $(0.5 \mathrm{~m})$ and LOD4 (0.2m or less) [47].

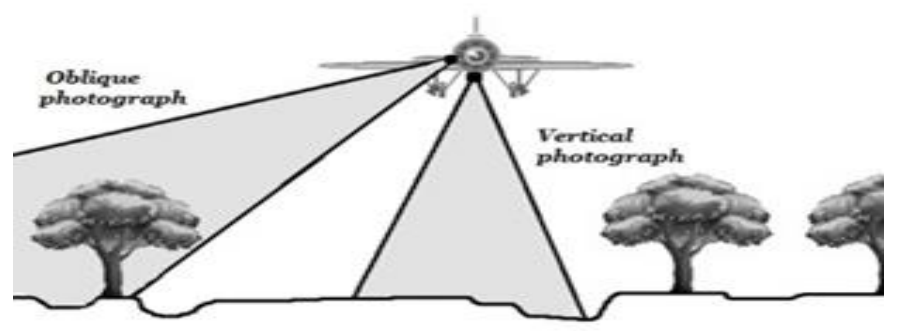

Fig. 17. Type of Aerial Photography.
Referring to cityGML (architectural models), this study has to fulfill the criteria of LOD2 successfully in order to show the positional and height accuracy at $2 \mathrm{~m}$ or better. Subsequently, the building has differentiated roof structures and thematically differentiated boundary surfaces (refer to Figure 13) which is the criteria of LOD2 [47]. Last but not least, this study managed to show that by using the integration of UAV and detailed surveying method, this study able to produce a 3D campus map for UTeM, Malacca.

\section{ACKNOWLEDGMENT}

The authors would like to express their profound gratitude to Faculty of Built Environment and Surveying (FABU), Universiti Teknologi Malaysia (UTM) for all the support that been provided. The authors also would like to thank Universiti Teknikal Malaysia Melaka (UTeM) for data collection (UAV aerial photo) and technical assistance in this study. Last but not least, the authors would like to thank UTM for providing the financial support through FRGS VOT 4F336, GUP-Tier 1 grant VOT 14H44, GUP-Tier 1 grant VOT 20H01, GUP Tier 2 grant VOT 12J47 and UTM-TDR 6.4 (T2).

\section{REFERENCES}

[1] Billen, R.; Cutting-Decelle, A.F.; Marina, O.; de Almeida, J.P.; Matteo, C.; Falquet, G.; Leduc, T.; Métral, C.; Moreau, G.; Perret, J.; et al. 3D City Models and urban information: Current issues and perspectives. In 3D City Models and Urban Information: Current Issues and Perspectives-European COST Action TU0801; EDP Sciences: Les Ulis, France, 2014; pp. 1-118.

[2] Zhu, Q.; Hu, M.; Zhang, Y.; Du, Z. Research and practice in threedimensional city modeling. Geo-Spat. Inf. Sci. 2009, 12, 18-24.

[3] Döllner, J.; Baumann, K.; Buchholz, H. Virtual 3D City Models as Foundation of Complex Urban Information Spaces. In Proceedings of the 11th International Conference on Urban Planning and Spatial Development in the Information Society, Vienna, Austria, 13-16 February 2006.

[4] Lancelle, M.; Fellner, D.W. Current issues on 3D city models. In Proceedings of the Proceedings of the 25th International Conference in Image and Vision Computing, Queenstown, New Zealand, 8-9 November 2010; pp. 363-369.

[5] Suveg, I.; Vosselman, G. Reconstruction of 3D building models from aerial images and maps. ISPRS J. Photogramm. Remote Sens. 2004, 58, 202-224.

[6] Haala, N.; Kada, M. An update on automatic 3D building reconstruction. ISPRS J. Photogramm. Remote Sens. 2010, 65, 570-580.

[7] Tomljenovic, I.; Höfle, B.; Tiede, D.; Blaschke, T. Building extraction from airborne laser scanning data: An analysis of the state of the art. Remote Sens. 2015, 7, 3826-3862.

[8] Blaschke, T. Object-based image analysis for remote sensing. ISPRS J. Photogramm. Remote Sens. 2010, 65, 2-16.

[9] Ledoux, H.; Meijers, M. Topologically consistent 3D city models obtained by extrusion. Int. J. Geogr. Inf. Sci. 2011, 25, 557-574.

[10] Arroyo Ohori, K.; Ledoux, H.; Stoter, J. A dimension-independent extrusion algorithm using generalised maps. Int. J. Geogr. Inf. Sci. 2015, 29, 1166-1186.

[11] Shahzad, M.; Zhu, X.X. Robust reconstruction of building facades for large areas using spaceborneTomoSAR point clouds. IEEE Trans. Geosci. Remote Sens. 2015, 53, 752-769.

[12] Zhu, X.X.; Shahzad, M. Facade reconstruction using multiviewspaceborneTomoSAR point clouds. IEEE Trans. Geosci. Remote Sens. 2014, 52, 3541-3552.

[13] Schmitt, M. Reconstruction of urban surface models from multi-aspect and multi-baseline interferometric SAR. Ph.D. Thesis, TechnischeUniversitätMünchen, München, Germany, 2014. 
[14] Still, U.; Soergel, U.; Thoennessen, U. Potential, and limits of InSAR data for building reconstruction in built-up areas. ISPRS J. Photogramm. Remote Sens. 2003, 58, 113-123.

[15] Thiele, A.; Wegner, J.D.; Soergel, U. Building reconstruction from multi-aspect InSAR data. In Remote Sensing and Digital Image Processing; Soergel, U., Ed.; Springer: Dordrecht, The Netherlands, 2010; pp. 187-214.

[16] Donkers, S.; Ledoux, H.; Zhao, J.; Stoter, J. Automatic conversion of IFC datasets to geometrically and semantically correct CityGML LOD3 buildings. Trans. GIS 2015, doi:10.1111/tgis.12162.

[17] Yin, X.; Wonka, P.; Razdan, A. Generating 3D building models from architectural drawings: A survey. IEEE Comput. Graph. Appl. 2009, 29, $20-30$.

[18] Lewis, R.; Séquin, C. Generation of 3D building models from 2D architectural plans. Comput.-Aided Des. 1998, 30, 765-779.

[19] Sirmacek, B.; Lindenbergh, R. Accuracy assessment of building point clouds automatically generated from iphone images. Int. Arch. Photogramm. Remote Sens. Spat. Inf. Sci. 2014, XL-5, 547-552.

[20] Rosser, J.; Morley, J.; Smith, G. Modelling of building interiors with mobile phone sensor data. ISPRS Int. J. Geo-Inf. 2015, 4, 989-1012.

[21] Besuievsky, G.; Patow, G. Recent advances on LoD for procedural urban models. In Proceedings of the 2014 Workshop on Processing Large Geospatial Data, Cardiff, UK, 8 July 2014.

[22] Tsiliakou, E.; Labropoulos, T.; Dimopoulou, E. Procedural modeling in 3D GIS environment. Int. J. 3-D Inf. Model. 2014, 3, 17-34.

[23] Müller, P.; Wonka, P.; Haegler, S.; Ulmer, A.; van Gool, L. Procedural modeling of buildings. ACM Trans. Graph. 2006, 25, 614-623.

[24] Smelik, R.M.; Tutenel, T.; Bidarra, R.; Benes, B. A Survey on procedural modelling for virtual worlds. Comput. Graph. Forum 2014, $33,31-50$.

[25] Biljecki, F.; Ledoux, H.; Stoter, J. Error propagation in the computation of volumes in 3D city models with the Monte Carlo method. ISPRS Ann. Photogramm. Remote Sens. Spat. Inf. Sci. 2014, II-2, 31-39.

[26] Martinovi'c, A. Inverse Procedural Modeling of Buildings. Ph.D. Thesis, KU Leuven, Leuven, Belgium, 2015.

[27] Over, M.; Schilling, A.; Neubauer, S.; Zipf, A. Generating web-based 3D City Models from OpenStreetMap: The current situation in Germany. Comput. Environ. Urban Syst. 2010, 34, 496-507.

[28] Goetz, M. Towards generating highly detailed 3D CityGML models from OpenStreetMap. Int. J. Geogr. Inf. Sci. 2013, 27, 845-865.

[29] Goetz, M.; Zipf, A. Towards defining a framework for the automatic derivation of 3D CityGML models from Volunteered Geographic Information. Int. J. 3-D Inf. Model. 2012, 1, 1-16.

[30] Rebelo C., Rodrigues A.M., Tenedório J.A., Goncalves J.A., Marnoto J. (2015) Building 3D City Models: Testing and Comparing Laser Scanning and Low-Cost UAV Data Using FOSS Technologies. In: Gervasi O. et al. (eds) Computational Science and Its Applications -- ICCSA 2015. ICCSA 2015. Lecture Notes in Computer Science, vol 9157.

[31] Eisenbeiß, H., 2009. UAV Photogrammetry, Dissertation Institute of Geodesy and Photogrammetry, ETH Zurich, Switzerland.

[32] Remondino, F., Barazzetti, L., Nex, F., Scaioni, M., Sarazzi, D., 2011, UAV photogrammetry for mapping and 3Dmodeling-current status and future perspectives, in: H. Eisenbeiss, M. Kunz, H. Ingensand (Eds.), Proceedings of the International Conference on Unmanned Aerial Vehicle in Geomatics (UAV-g) 2011, Zurich, Switzerland.
[33] Zongjian, L.I.N., 2008, UAV for mapping-low altitude photogrammetric survey, International Archives of Photogrammetry and Remote Sensing, Beijing, China.

[34] Ouédraogo, M.M., Degré, A., Debouche, C., Lisein, J., 2014. The evaluation of unmanned aerial system-based photogrammetry and terrestrial laser scanning to generate DEMs of agricultural watersheds. Geomorphology, 214, pp. 339-355.

[35] H. Eisenbeiß, UAV Photogrammetry, Dissertation Institute of Geodesy and Photogrammetry, ETH Zurich, Switzerland, 2009.

[36] F. Remondino, L. Barazzetti, F. Nex, M. Scaioni, D. Sarazzi, UAV photogrammetry for mapping and 3Dmodeling-current status and future perspectives, in: H. Eisenbeiss, M. Kunz, H. Ingensand (Eds.), Proceedings of the International Conference on Unmanned Aerial Vehicle in Geomatics (UAV-g) 2011, Zurich, Switzerland, September 2011.

[37] L.I.N. Zongjian, UAV for mapping-low altitude photogrammetric survey, International Archives of Photogrammetry and Remote Sensing, Beijing, China, 2008.

[38] B.P. Hudzietz, S. Saripalli, An experimental evaluation of 3d terrain mapping with an autonomous helicopter, in: H. Eisenbeiss,M. Kunz, H. Ingensand (Eds.), Proceedings of the International Conference on Unmanned Aerial Vehicle in Geomatics (UAV-g) 2011, Zurich, Switzerland, September 2011.

[39] D. Bulatov, P. Solbrig, H. Gross, P. Wernerus, E. Repasi, C. Heipke, Context-based urban terrain reconstruction from UAV-videos for geoinformation applications, in: H. Eisenbeiss,M. Kunz, H. Ingensand (Eds.), Proceedings of the International Conference on Unmanned Aerial Vehicle in Geomatics (UAV-g) 2011, Zurich, Switzerland, September 2011.

[40] F. Neitzel, J. Klonowski, Mobile 3D mapping with a low-cost UAV system, Int. Arch. Photogramm. Remote. Sens. Spat. Inf. Sci. 38 (2011) $1-6$.

[41] Zhiguang Ding, Xinsheng yan, Huiguang Chen. Study on the Rapid 3D Modeling of Jiangmen City Based on Tilting Skill of Unmanned Aerial Vehicle [J]. Urban Survey, 2016 (4): 72-78.

[42] B.P. Hudzietz, S. Saripalli, An experimental evaluation of 3d terrain mapping with an autonomous helicopter, in: H. Eisenbeiss,M. Kunz, H. Ingensand (Eds.), Proceedings of the International Conference on Unmanned Aerial Vehicle in Geomatics (UAV-g) 2011, Zurich, Switzerland, September 2011.

[43] Eisenbeiss H. 2011. The potential of unmanned aerial vehicles for mapping. In Photogrammetric Week '11, Fritsch D (ed.). Wichmann: Berlin/Offenbach; 135-145.

[44] Gatziolis, D., J. F. Lienard, A. Vogs, and N. S. Strigul. 2015. "3D Tree Dimensionality Assessment Using Photogrammetry and Small Unmanned Aerial Vehicles." PLoS One 10 (9): e0137765.

[45] Tahar, K.2015. Height accuracy based on different RTK GPS method for Ultra-Light Aircraft Images. The International Archives of the Photogrammetry, Remote Sensing and Spatial Information Sciences 43, $1-6$.

[46] Hidayat H and Cahyono A B 2016 Combined Aerial and Terrestrial Images For Complete 3D Documentation Of Singosari Temple Based On Structure From Motion Algorithm IOP Conference Series: Earth and Environmental Science 47.

[47] Biljecki, I. F. 2013. "The Concept of Level of Detail in 3D City Models." PhD Research Proposal GISt Report No. 62. 